\title{
PENGARUH PEMBERIAN TENS DAN MYOFASCIAL RELEASE TERHADAP PENURUNAN NYERI LEHER MEKANIK
}

\author{
Pajar Haryatno, Heru Purbo Kuntono \\ Kementerian Kesehatan Politeknik Kesehatan Surakarta Jurusan Fisioterapi
}

\begin{abstract}
The pain, TENS, Myofascial Release. The research objective was to determine the effect of administration of TENS and Myofascial Release to decline Mechanical Neck Pain. This study design is one group pre and post test design. Subjects and treatment are 20 people who suffer from neck pain mechanic who met the study criteria given TENS and myofascial release treatment for 2 weeks. Points clinical research "Fitasoma" Colomadu, Karanganyar, Central Java. The results of the significance of pain before and after treatment have a value of $p=0.000(p<0.05)$, which means that there is influence of TENS and Myofascial Release to the reduction of mechanical neck pain. TENS and Myofascial Release have the effect of reducing pain in patients with mechanical neck pain.
\end{abstract}

Keywords: Pain, TENS, Myofascial Release

Abstrak: Nyeri, TENS, Myofascial Release. Tujuan penelitian adalah untuk mengetahui Pengaruh Pemberian TENS dan Myofascial Release terhadap Penurunan Nyeri Leher Mekanik. Desain penelitian ini adalah one group pre and post test design. Subjek dan perlakuan adalah 20 orang yang menderita nyeri leher mekanik yang memenuhi kriteria penelitian diberikan perlakuan TENS dan myofascial release selama 2 minggu. Tempat penelitian klinik "Fitasoma" Colomadu, Karanganyar, Jawa Tengah. Hasil signifikansi nyeri sebelum dan setelah perlakuan memiliki nilai $\mathrm{p}=0,000(\mathrm{p}<0,05)$, yang berarti ada pengaruh TENS dan Myofascial Release terhadap penurunan nyeri leher mekanik. TENS dan Myofascial Release memiliki pengaruh untuk menurunkan nyeri pada penderita nyeri leher mekanik.

Kata Kunci: Nyeri, TENS, Myofascial Release

PENDAHULUAN

Dalam kehidupannya, manusia melakukan berbagai aktivitas untuk memenuhi kebutuhannya, baik itu kebutuhan fisik, mental, spiritual dan sosial misalnya bekerja, olah raga, beraktivitas sosial, beribadah, dan lain lain. Aktivitas berlebihan akan menimbulkan efek pada seseorang, seperti keluhan pada sistem otot (musculoskeletal) berupa keluhan rasa sakit, nyeri, pegal-pegal dan lainnya.
Nyeri leher (neck pain) merupakan keluhan yang sangat umum, dimana $70 \%$ populasi pasti pernah mengalami nyeri leher. Sehingga nyeri leher merupakan kasus musculoskeletal terbesar kedua setelah nyeri punggung bawah (Low Back Pain) (Cooper Grant, 2006). Nyeri muskuloskeletal dileher merupakan masalah kesehatan pada masyarakat modern. Sebuah studi menunjukkan prevalensi nyeri muskuloskeletal di leher pada masyarakat selama 1 tahun besarnya 
$40 \%$ dan prevalensi ini lebih tinggi pada wanita. Selama 1 tahun, prevalensi nyeri muskuloskeletal di daerah leher pada pekerja besarnya berkisar antara 60\% $70 \%$ dan wanita ternyata juga lebih tinggi dibandingkan pria (Ariens,2001).

Nyeri leher yang banyak terjadi pada masyarakat umumnya merupakan nyeri leher mekanik. Nyeri leher mekanik adalah nyeri leher yang tidak menyebar sampai anggota gerak atas, nyeri berlokasi pada leher, area oksipital atau dasar tengkorak dan bahu bagian belakang. Nyeri leher mekanik dapat disebabkan oleh beberapa faktor, antara lain : postur yang salah, kecemasan, stress, dan gerakan yang berlebihan. Keluhan yang dirasakan pada umumnya adalah sakit di daerah leher dan kaku, nyeri pada otototot leher, dapat juga terjadi sakit kepala dan migraine. Hal itu dapat menimbulkan ketidaknyamanan, penurunan kualitas hidup, dan penurunan aktivitas kerja pada individu (Elizabeth, 2009).

Pemendekan otot (muscle contracture) sering terjadi pada otot postural atau otot tonish, sehingga sering mengakibatkan gangguan keseimbangan otot dalam mempertahankan posisi postural (musculair disbalance). Akibat dari musculair disbalance akan selalu diikuti hypertonus pada otot otot yang mengalami pemendekan (contracture). Hypertonus pada otot yang terjadi terus menerus merupakan salah satu pencetus nyeri myofascial.Otot-otot postural leher yang sering terjadi pemendekan yaitu $\mathrm{m}$. $\mathrm{m}$. Semi spinalis capitis, m. Sternocleido mastoideus, m. Scaleni, m. Levator scapula dan m. Trapezius upper. Sindrom nyeri myofascial adalah nyeri otot rangka yang ditandai oleh nyeri local dan nyeri kiriman (reffered pain). Serta kehadiran titik titik pemicu myofascial. Patofisiologi sindrom nyeri myofascial tidak dipahami dengan jelas. Meskipun demikian, sejumlah perubahan morfologis, fitur neurosensori, neurotransmitter, gangguan motorik dan faktor elektrofisiologis dianggap terlibat didalam patogenesisnya.

Berdasarkan permasalahan pada penderita nyeri leher mekanik yaitu adanya pemendekan otot postural namun saat ini dalam penanganan terapeutik untuk nyeri leher mekanik dengan medikamentosa dan beberapa teknik fisioterapi selama ini kurang efektif sehingga hasil terapi yang didapatkan kurang optimal.

Menurut Marshall

pendekatan fisioterapi secara spesifik dengan TENS dan Myofascial release dilaporkan mendapatkan hasil yang siqnifikans untuk mengurangi nyeri leher mekanik.

Maka berdasarkan latar belakang tersebut, penatalaksanaan fisioterapi dengan TENS dan myofascial release dapat diberikan untuk mengurangi nyeri sekaligus memberikan pengobatan secara kaustif sehingga hasilnya lebih efektif.

\section{METODE PENELITIAN}

Jenis penelitian ini merupakan penelitian pre eksperimental . Desain yang dipilih dalam penelitian ini adalah one group pre test and post test design karena hanya satu kelompok yang diambil sebagai subjek penelitian tanpa ada kelompok pembanding Penelitian ini dilaksanakan di Klinik Fitasoma Colomadu pada bulan April sampai dengan Juni 2015.

Subjek dalam penelitian ini adalah seluruh pasien nyeri leher mekanik yang berobat jalan Klinik Fisioterapi "Fitasoma" Colomadu pada periode April sampai dengan Juni tahun 2015 
yangmemenuhi kriteria inklusi sebagai berikut : (1) pasien dengan keluhan nyeri leher, (2) tidak ada penjalaran nyeri pada salah satu maupun kedua tangan, (3) adanya spasme pada otot-otot ekstensor leher, (4) usia 20-65 tahun, (5) tekanan darah normal. Sedangkan kriteria ekslusi meliputi: (1) keganasan, (2) luka terbuka, (3) deep vein trombhosis, (4) hiperaestesi, (5) diabetes yang telah lanjut, (6) terapi kortison atau pengencer darah, (7) cedera akut atau area paska bedah yang masih akutpassive stretching. Kriteria drop out antara lain: (1) tidak mengikuti terapi pada pemeriksaan akhir, (2) nyeri leher bertambah hebat melebihi batas toleransi pasien.

Penelitian ini terdiri dari 2 variabel yaitu variabel bebas dalam penelitian ini adalah TENS $\left(\mathrm{X}_{1}\right)$ dan myofascial release $\left(\mathrm{X}_{2}\right)$ dan sedangkan variabel terikat dalam penelitian ini adalah derajat nyeri $\left(\mathrm{Y}_{1}\right)$.

Pengumpulan data dalam penelitian ini dengan data primer berupa hasil pengukuran derajat nyeri dengan skala VAS.

Data yang telah terkumpul dilakukan uji non parametrik dengan uji Wilcoxon untuk mengetahui pengaruh pemberian TENS dan myofascial release terhadap penurunan nyeri leher mekanik.

\section{HASIL PENELITIAN}

Subjek pada penelitian ini adalah pasien nyeri leher mekanik yang berobat jalan Klinik Fisioterapi "Fitasoma" Colomadu pada periode April sampai dengan Juni tahun 2015 yang memenuhi kriteria inklusi dan eksklusi yang sudah ditentukan dan telah dilakukan pemeriksaan pada bulan Mei 2015. Jumlah subjek penelitian yang memenuhi syarat adalah 20 orang. Subjek sebanyak 20 orang kemudian diberikan perlakuan
TENS dan myofascial release. Semua subjek telah bersedia menandatangani persetujuan (informed consent) untuk menjadi subjek penelitian. Sebelum diberikan intervensi, subjek penelitian dilakukan pemeriksaan VAS untuk diketahui nilai nyeri. Selama pelaksanaan penelitian, tidak ada subjek yang drop out. Dari ke 20 subjek penelitian diberikan intervensi terapi selama 2 minggu, seminggu 3 kali. Semula diberikan pre test dan setelah perlakuan diukur pada saat akhir sebagai post test. Gambaran karakteristik subjek dapat dilihat sebagai berikut :

1. Umur

\section{Tabel 1}

Deskripsi Umur Subjek Penelitian

\begin{tabular}{ccc}
\hline Umur Subjek & $\begin{array}{c}\text { Jumlah } \\
\text { Subjek }\end{array}$ & Persentase (\%) \\
\hline$<50$ tahun & 7 & 35 \\
$>50$ tahun & 13 & 65 \\
\hline Total & 20 & 100.0 \\
\hline \multicolumn{2}{c}{ Berdasarkan } & 1
\end{tabular}

menunjukkan bahwa mayoritas dari 20 berumur $>50$ tahun sebanyak 13 orang $(65 . \%)$, sedangkan yang berumur $<50$ tahun sebanyak 7 orang (35\%).

\section{Jenis Kelamin}

\section{Tabel 2}

Deskripsi Jenis Kelamin Subjek Penelitian

\begin{tabular}{|c|c|c|}
\hline $\begin{array}{c}\text { Jenis } \\
\text { Kelamin } \\
\end{array}$ & $\begin{array}{l}\text { Jumlah } \\
\text { Subjek }\end{array}$ & Persentase $(\%)$ \\
\hline Laki - laki & 5 & 25 \\
\hline Perempuan & 15 & 75 \\
\hline Total & 20 & 100.0 \\
\hline
\end{tabular}
menunjukkan bahwa dari 20 orang subjek, 5 orang $(25 \%)$ subjek penelitian berjenis kelamin laki-laki dan 15 orang subjek berjenis kelamin perempuan. Mayoritas 
subjek berjenis kelamin perempuan, dengan frekuensi $75 \%$.

Analisis bivariat pada penelitian ini dimaksudkan untuk menguji adanya pengaruh pemberian TENS dan Myofascial Release terhadap penurunan nyeri leher mekanik. Berdasarkan hasil uji statistik menggunakan Wilcoxon dapat dipaparkan seperti pada tabel 3.

Tabel 3

Hasil Uji Wilcoxon Pengaruh Tens Dan Myofascial Release Terhadap Penurunan Nyeri

\begin{tabular}{|c|c|c|c|c|}
\hline \multicolumn{5}{|c|}{ Ranks } \\
\hline & & $\mathrm{N}$ & $\begin{array}{l}\text { Mean } \\
\text { Rank }\end{array}$ & $\begin{array}{c}\text { Sum of } \\
\text { Ranks }\end{array}$ \\
\hline \multirow{4}{*}{$\begin{array}{l}\text { Post Test } \\
\text { Minggu } \\
\text { ke } 1 \text { - Pre } \\
\text { Test }\end{array}$} & $\begin{array}{l}\text { Negative } \\
\text { Ranks }\end{array}$ & $20^{\mathrm{a}}$ & 10.50 & 210.00 \\
\hline & $\begin{array}{l}\text { Positive } \\
\text { Ranks }\end{array}$ & $0^{\mathrm{b}}$ & .00 & .00 \\
\hline & Ties & $0^{c}$ & & \\
\hline & Total & 20 & & \\
\hline \multirow{4}{*}{$\begin{array}{l}\text { Post Test } \\
\text { Minggu } \\
\text { ke } 2 \text { - Pre } \\
\text { Test }\end{array}$} & $\begin{array}{l}\text { Negative } \\
\text { Ranks }\end{array}$ & $20^{\mathrm{d}}$ & 10.50 & 210.00 \\
\hline & $\begin{array}{l}\text { Positive } \\
\text { Ranks }\end{array}$ & $0^{\mathrm{e}}$ & .00 & .00 \\
\hline & Ties & $0^{\mathrm{f}}$ & & \\
\hline & Total & 20 & & \\
\hline
\end{tabular}

Dari hasil analisis Wilcoxon test, diperoleh nilai mean sebelum perlakuan sebesar 6,95 dan setelah perlakuan nilai mean menjadi 10,50. Sedangkan nilai standar deviasi sebelum perlakuan 1,099 dan setelah perlakuan 1,989 . Pada uji beda ini didapat nilai probabilitas $(p)=0,000$ atau $\mathrm{p}<0,05$. Hal ini menunjukkan bahwa ada perbedaan yang signifikan pemberian TENS dan myofascial release terhadap penurunan nyeri leher mekanik.

Pengujian hipotesis diperoleh hasil-hasil sebagai berikut : (1) Terdapat perbedaan yang bermakna antara pre test dengan post test minggu ke 1 untuk nyeri
( $\mathrm{p}<0.05)$, dan dengan post test minggu ke 2 untuk nyeri $(\mathrm{p}<0.05)$.

\section{PEMBAHASAN}

1. Ada Pengaruh TENS terhadap penurunan nyeri leher mekanik

TENS banyak digunakan untuk solusi kasus nyeri leher mekanik. TENS merupakan pengabungan perangkat kecil untuk mengarahkan pulsa listrik ringan ke saraf di area yang sakit. Selama penanganan stimulasi dengan TENS, elektroda diletakkan atau ditempelkan pada kulit didaerah yang mengalami keluhan nyeri (triggerpoint). Elektroda dihubungkan dengan kabel ke stimulator bertenaga listrik. Beberapa unit TENS bekerja dengan cara memblokir impuls nyeri melalui stimulasi serabur saraf besar. Jenis lain TENS bekerja dengan menyebabkan tubuh melepaskan endorphin (zat kimia saraf yang terjadi secara alami dalam otak yang memiliki sifat menghilangkan rasa sakit).

TENS konvensional memiliki frekuensi stimulasi yang tinggi $(10-200$ pps) dan intensitas rendah. Durasi pulsa (hingga 100 - 200 mikro detik) (Parjoto, 2006). TENS konvensional menghasilkan efek analgesia terutama melalui mekanisme segmental yaitu dengan jalan mengaktivasi serabut A- $\square$ yang selanjutnya akan menginhibisi neuron nosiseptif di kornu posterior medulla spinalis, hal ini mengacu pada teori gerbang control.

Penelitian ini digunakan TENS yang bersifat nosiseptif yang akan memacu algogenic chemical pain (histamine, prostaglandin, bradikinin) yang berperan meneruskan stimulus nosiseptif dengan merangsang reseptor enkepalin. Rangsangan pada reseptor enkepalin merupakan stimulus prodromik 
yang akan diikuti pembebasan endorphin sehingga nyeri berkurang. Pada sisi lain aktivasi dari algogenic chemical pain akan memacu substan $\mathrm{P}$ yang membuat vasodilatasi pembuluh darah kapiler (Gersh, 1992).

Aplikasi TENS dapat mengurangi keluhan nyeri leher dimana aktifitas sel nosiseptor di kornu dorsalis saat TENS diaplikasikan pada area somatic dalam bentuk inhibisi pre dan post sinapsis, hal ini sesuai dengan penelitian yang dilakukan Garrison dan Foreman (1994). TENS dengan aplikasi segmental simpatis dapat mengurangi nyeri kronis pada kondisi nyeri leher mekanik melalui mekanisme ,(1) efek antidromik yang bermafat untuk memperbaiki dan meningkat proses recovery jarigan lunak melalui respon vasodilatasi kapiler, (2) efek prodomik yang bermanfaat terhadap aktivasi beta endorphin dan serotonin ntuk membantu menurunkan keluhan nyeri pada kondisi musculoskeletal termasuk nyeri leher mekanik. . Ini sejalan dengan penelitian yang dilakukan oleh Nig Q J Hosp Med, 2008 pada 8 subyek TTH usia 20-50 tahun diberikan TENS 3 kali 116 seminggu selama 10 minggu ( $30 \mathrm{x}$ terapi) untuk mengevaluasi nyeri dengan parameter VAS, disabilitas fungsional dengan HDI dan ROM dengan goniometer. Diperoleh hasil yang signifikan untuk mengurangi nyeri dan perbaikan disabilitas fungsional dan ROM.

2. Ada Pengaruh Myofascial Release terhadap penurunan nyeri leher mekanik.

Uji beda pre dan post test pada kelompok II menggunakan uji Wilcoxon diperoleh hasil yang signifikan $\mathrm{p}=0,000$ $(\mathrm{p}<0,05)$. Hal ini menunjukan bahwa terdapat perbedaan nilai hasil pengukuran nyeri yang bermakna setelah diberikan myofascial release. Hasil penelitian ini mendukung teori dari Grant dan Riggs pada tahun 2009 menyatakan bahwa myofascial release technique dapat berperan untuk memberikan stretch atau elongasi pada struktur otot dan fascia dengan tujuan melepas adhesion atau perlengketan, mengurangi nyeri dengan gate control theory, memulihkan kualitas cairan pelumas dari jaringan fasia, mobilitas jaringan dan fungsi normal sendi. Mengacu pada teori yang disampaikan oleh Werenski (2011) dimana penelitian ini menujukan bahwa myofascial release dapat menurunken nyeri dengan proses ketika adanya rangsangan atau stimulus akan mengaktivasi saraf berpenampang tebal , dimana saraf berpenampang tebal itu akan berjalan menuju 79 spinal di bagian PHC yang berada di substansia galatinosa. Dimana ketika ada sebuah rangsangan pada substansia galatinosa maka substansia galatinosa tersebut akan aktif, dan apabila substansia galatinosa tersebut aktif maka geat akan tertutup. Dimana jika geat tersebut tertutup maka sel $\mathrm{T}$ (transmition sel) tidak akan aktif, sehingga rangsang nyeri tidak akan sampai ke otak. Selain itu mengacu pada teori yang dikemukakan oleh Manuel et al (2008) bahwa myofascial release juga membantu untuk melepaskan perlengketan jaringan sementara disisi lain, akan terjadi aktivasi dari saraf parasimpatik yang akan membuat aliran darah diarea tersebut lancar sehingga akan menimbulkan efek sedative yang akan membuat rasa nyeri berkurang atau hilang. Penelitian sebelumnya telah dibuktikan oleh Werenski pada tahun 2011 dalam studi literaturnya yang berjudul The Effectifness of Myofascial 
ReleaseTechniques in the Treatment of Myofascial Pain bahwa penerapan myofascialrelease technique dapat mengurangi nyeri muskuloskeletal dengan menggunakan Gate Control Theory, interpersonal attention, parasympathetic respon pada saraf otonom, dan pelepasan serotonin. Fryer et al pada tahun 2005 menyatakan bahwa secara fisiologis adanya pelepasan biokimia dari tubuh seperti histamin dan serotonin akan menyebabkan vasodilatasi dan permeabilitas pembuluh darah yang secara mekanis melakukan penataan kembali pada struktur jaringan pada otot. Hasil penelitian ini sejalan dengan penelitian yang dilakukan oleh Fryer et al pada tahun 2005, jumlah subjek 37 subjek dengan trigger point upper trapezius, didapatkan hasil bahwa myofascial release sangat efektif dalam mengurangi trigger point pada otot upper trapezius.

\section{KESIMPULAN DAN SARAN}

Berdasarkan penelitian yang dilakukan pada 20 orang penderita nyeri leher mekanik yang diberikan TENS dan myofascial release selama 2 minggu, dimana nyeri dievaluasi dengan VAS Scale, diperoleh kesimpulan sebagai berikut.

Pemberian TENS dan myofascial release pada penelitian ini memiliki pengaruh terhadap penurunan nyeri pada penderita nyeri leher mekanik yang diukur dengan VAS Scale. Hal ini juga dapat diketahui dari hasil analisis statistik dengan menggunakan wilcoxon test. Diperoleh nilai $\mathrm{p}=0,000$ yang artinya secara bermakna ada pengaruh yang diberikan TENS dan myofascial release terhadap penurunan nyeri leher mekanik.
Dari hasil analisis yang didapatkan, TENS dan myofascial release memiliki manfaat untuk mengurangi nyeri pada penderita nyeri leher mekanik

Saran dari penelitian ini adalah (1) TENS dan myofascial release dapat digunakan sebagai modalitas tambahan pada penderita nyeri leher mekanik untuk mengurangi nyeri, (2) diperlukan penelitian yang lebih lanjut dengan subjek yang lebih banyak, waktu yang lebih panjang dan adanya follow up setelah diberikan perlakuan untuk melihat manfaat TENS dan myofascial release dalam jangka waktu panjang.

\section{DAFTAR RUJUKAN}

Alvarez, D. J., 2002; Trigger Points: Diagnosis and Management, American Family Physician, vol. 65, hal. 653-660.

Ahmed , 2011 ; Effect of Transcutenous Electrical Nerve Stimulation (TENS) on Patients With Low Back Pain, Retreived December, 30, $2013 \quad, \quad$ from http://www.banglajol.info/index.ph p/JAFMC/article/download/10393/ 7679

Barnes JF, Marzano A. 1990; Myofascial Release: The Search for Excellence; Rehabilitation Services; vol. 37, hal. 56-57, 125133.

Barness J.F., 2010; Myofascial Relese: Definition; diakses tanggal 28/12/2013, dari http://www.myofascialrelease.com

Basjirrudin A, 2002; Clinical Management and Neck pain; Majalah Neuroma, hal. 13-16.

Cubick et al, 2011; Sustained Myofascial Release as a Treatment for Patient with Complication of Rheumatoid 
Artritis and Collagenous Colitis : A Case Report Study; Univercity of Miami, Miami.

Jensen, M., 2003; The Validity and Reliability of Pain Measures in Adults With Cancer; Journal of American Pain Society, vol. 4, no. 1, hal. 3-20.

Khaldikar , A. , 2005 ; Transcutaneous Electrical Nerve Stimulation (TENS) for low back pain. Cochrane Collaboration.

Marshall et al, 2009; Evaluating the effectiveness of Myofascial Release to reduce pain in people with Chronic Fatigue Syndrome (CFS): A Pilot Study; Glasgow Caledonian University, Glasgow.
Murtagh.J., and Kenna.C., 1997; Migration of The Nucleus Pulposus within The Intervertebral Disc During Flexion and Extention of Spine; Spine, hal.2753-2757.

Parjoto, Slamet, 2006 ; Terapi Listrik untuk Modulasi Nyeri, Ikatan fisioterapi cabang Semarang, Semarang.

Paolini J., 2009; Review of Myofascial Release as an Effective Massage Therapy Technique; Athletic Therapy Today, Vol. 14, hal. 3034. 